\title{
Drug Shop Intervention to Enhance Knowledge, Attitude, and Practices of Patent Medicine Vendors for the Control of COVID-19 In Southeastern Nigeria
}

\author{
Uchechukwu Madukaku Chukwuocha,* Gregory Ndubeze Iwuoha, Onyeka Francis Ashinze, Princewill Ugochukwu Njoku, \\ Chidera Chisom Obasi, Evelyn Ifezue Adey, and Ikechukwu Nosike Simplicius Dozie \\ Department of Public Health, Federal University of Technology, Owerri, Imo State, Nigeria
}

\begin{abstract}
Drug shops are the first point of care for most community members in low-resource countries. Because of symptomatic similarities with common illnesses such as malaria, probable coronavirus disease 2019 (COVID-19) cases may seek care at drug shops, where the knowledge and skills required to handle it may be lacking, thereby fostering community spread of the disease. This single-arm study provided an intervention to improve COVID-19-related knowledge, attitude, and practices of patent medicine vendors (PMVs) in 97 participating drug shops selected through cluster sampling in Owerri, southeastern Nigeria. The intervention involved a drug shop sensitization using information, education, and communication material, as well as training on the use of a risk assessment checklist to identify probable COVID-19 cases and to take appropriate action. Data were collected to determine the effect of this intervention using a pre-tested questionnaire and practice observation checklist, first at baseline and then 3 months post-intervention. Data analysis involved exploratory analysis and the $t$-test to determine pre- and post-intervention mean score differences at the 5\% $\alpha$ level. There was post-intervention knowledge improvement on the COVID-19 causative pathogen (98.1\% post-intervention versus $61.9 \%$ pre-intervention) and disease transmissibility from person to person (95.9\% postintervention versus $81.4 \%$ pre-intervention) among other knowledge domains. There was significant post-intervention improvement for positive attitude, with a mean gain score of $2.8 \pm 1.7(\mathrm{t}=4.4, P=0.005)$, and preventive practices, with a mean gain score of $6.0 \pm 4.7(\mathrm{t}=4.1, P=0.007)$. Engaging patent medicine vendors in the pandemic response plans through targeted interventions such as drug shop intervention could prove vital in the fight against COVID-19.
\end{abstract}

\section{INTRODUCTION}

Coronavirus disease 2019 (COVID-19) is caused by severe acute respiratory syndrome coronavirus 2 (SARS-CoV-2), which spreads from person-to-person mainly through contact with respiratory droplets of an infected person. ${ }^{1,2}$ People infected with SARS-CoV-2 may be asymptomatic or present with flu-like symptoms such as cold, sore throat, headache, cough, fever, shortness of breath, fatigue, and pneumonia. It has been argued that the disease is more severe in the elderly than in young people. ${ }^{3}$ People burdened with underlying chronic diseases and the immunocompromised are also believed to be at greater risk of fatality. ${ }^{4}$ Because of the lack of a definite cure, and vaccines just emerging, combined with international travel and movement of goods and services, the disease spread quickly to all parts of the globe, including sub-Saharan Africa, which is home to many poor and underdeveloped countries. ${ }^{5,6}$ Nigeria's first confirmed case of COVID-19 was reported on February 27, 2020; by April 2020, more than 9,500 cases, with 273 fatalities, were already confirmed. ${ }^{7}$ Since then, the disease has been spreading all over the country with increasing morbidity and mortality. According to the WHO, one of the core strategic responses to mitigating the effects of the pandemic is risk communication and community engagement. ${ }^{8}$ Already there have been several rumors and misconceptions in Nigeria that COVID-19 is a "white man's" disease and does not affect black people, or people who have never been abroad. ${ }^{9}$ This kind of orientation can disrupt the implementation of interventions and adoption of safety guidelines, and may aid in fostering the spread of infection.

\footnotetext{
* Address correspondence to Uchechukwu Madukaku Chukwuocha, Department of Public Health, Federal University of Technology, Owerri, PMB 1526, Owerri, Imo State, Nigeria. E-mail: uchukwuocha@gmail.com
}

Engaging and enlightening the public on key issues bordering what is known and unknown about an outbreak, prevention guidelines, as well as new protocols are key to any emergency response. In various developing, underdeveloped, and resource-poor countries such as Nigeria, where the health and social infrastructures are weak, and affect the pattern of care-seeking negatively, private-sector drug shops are usually the first points of care for community members. They play an important role in delivering basic health services to the public ${ }^{10,11}$ and are operated by individuals designated as patent medicine vendors (PMVs). PMVs are drug distributors and sellers without formal pharmacy training who are licensed to retail proprietary and over-the-counter drugs, particularly for profit. ${ }^{12}$ They dominate most remote communities in Nigeria, including rural, suburban, and urban centers, and enjoy a certain level of respect and trust from community members. They are also generally regarded as a convenient source of relevant and correct health information.

Given that the symptoms of COVID-19 overlap those of common diseases such as malaria ${ }^{12}$ and the common cold, community members will most likely present with these same symptoms at private drug shops, where they usually obtain treatment. This makes drug shops potential points of infection and emphasizes the vital role of PMVs in the prevention of community transmission of COVID-19. It is therefore essential that these PMVs are adequately informed and trained through deliberate and targeted means to take necessary measures that will aid in curbing the community transmission of COVID19 , particularly from the drug shops. These measures include crowd management and physical distancing in the drug shop, use of gloves and face masks, frequent handwashing with soap and water, as well as disinfection with sanitizers after attending to customers. Other measures include the proper disposal of gloves and face masks after use, asking the right questions, educating the public, and following up by reporting suspected cases promptly to designated health authorities for 
appropriate action. Therefore, this study aimed at enhancing the knowledge, attitude, and practices of PMVs through a drug shop intervention to involve them in the control of COVID-19 in southeastern Nigeria.

\section{METHODS}

Study design. This study was a single-arm intervention carried out between April and September 2020 to enhance the knowledge, attitude, and practices of PMVs by engaging and involving them in the control of the community transmission of COVID-19. Study participants were mobilized via engagement with the leadership of the National Association of Patent Medicine Vendors, Imo State Chapter, and subsequent text messaging in line with social and physical distancing guidelines.

Study area. The study was conducted in Owerri, Imo State, southeastern Nigeria. Imo State lies within latitude $4^{\circ} 45^{\prime} \mathrm{N}$ and $7^{\circ} 15^{\prime} \mathrm{N}$, and longitude $6^{\circ} 50^{\prime} \mathrm{E}$ and $7^{\circ} 25^{\prime} \mathrm{E}$, and measures $5,100 \mathrm{~km}^{2}$. The state has an estimated population of $4.8 \mathrm{mil}-$ lion people and a population density that varies from 230 to 1,400 people $/ \mathrm{km}^{2}$. Although there are a good number of health facilities in Imo, including hospitals and primary health-care centers, they are often either non-functional, ill-equipped, or understaffed. ${ }^{13}$ Private-sector drug shops dominate most parts of the state and supplement ideal health-care services in the area.

Study population. This study involved operators of private-sector drug shops in Owerri, registered with the Imo State Ministry of Health and the National Association of Patent Medicine Vendors. The drug shops totaled 904, serving about 1.4 million residents.

Sample size estimation. To estimate the study sample size $(n)$, we considered the appropriate sample size computation technique at a $5 \%$ significant level:

$$
n=\frac{p_{1} \times\left(100-p_{1}\right)+p_{2} \times\left(100-p_{2}\right)}{\left(p_{2}-p_{1}\right)^{2}} \times f(\alpha, \beta),
$$

where $p_{1}$ and $p_{2}$, respectively, represent known success rates for knowledge, attitude and practices (KAP) in the pre- and postintervention groups, while $\alpha$ and $\beta$ represent the type 1 error and the type 2 error respectively.

Because there were no prior studies in Nigeria on knowledge, attitude, and practices for the control of community transmission of COVID-19 among drug shops, we assumed level $p_{1}=50 \%$ and targeted a post-intervention improvement of $70 \%$ in 3 months $\left(p_{2}=70 \%\right)$. This led to a $20 \%$ minimum significant difference, at $80 \%$ power $(f(\alpha, \beta)=7.9)$. A sample size of 91 drug shops was therefore estimated for the study. To account for the possibility of loss to follow-up, an additional $5 \%$ of the estimated sample was added, leading to a total number of 97 drug shops as the final estimated sample size.

Sampling technique. A two-stage cluster sampling technique was used to select the drug shops based on the probability proportional to the number of drug shops at each cluster of electoral wards in the study area. First, wards were selected through simple random sampling. This was followed by a systematic sampling of the required number of drug shops and their corresponding operators from each ward, who were then targeted for a physical engagement/interview.

The intervention. The intervention involved drug shop-todrug-shop education and advocacy using information, education, and communication (IEC) material designed according to the guidelines of the $\mathrm{WHO}$ and the Nigerian Center for Disease Control (NCDC) on COVID-19. Furthermore, the drug shop operators were trained on probable case detection using a modified NCDC checklist. These activities were carried out during visits by two research team members per drug shop after they were updated adequately on the subject, protocols, and procedures. The contact time for each visit lasted an average of 1 hour. Study team members complied with all COVID-19 prevention guidelines and ensured these measures were also established at every drug shop visited during the intervention. The IEC material was a single page of material with four sections: 1) overview of COVID-19; 2) risk factors of COVID-19 in the drug shop, including factors that will enable community spread from the drug shop; 3) mitigation of risk factors to prevent community spread from the drug shop; and 4) actions to take on encountering a suspected case, including proper engagement of clients on the COVID-19 subject.

PMVs were also trained to use the modified NCDC checklist $^{7}$ to extract information from clients who presented with symptoms associated with COVID-19. Questions on the form included experience of symptoms such as fever, headache, dry cough, and shortness of breath. Other questions were about recent visits to COVID-19 hot spots and contact with persons returning from COVID-19 hot spots. Each question on the checklist had a score. The total of the scores pulled according to the questions answered was expected to be calculated and compared with given thresholds to determine whether a client was a suspected case. If a case is suspected, the PMV is expected to counsel and extract the necessary information from the person, isolate the person in a safe, designated space in the drug shop, and report promptly to appropriate health authorities for extraction. The IEC material as well as copies of the checklist were made available to the PMVs for reference purposes and the determination of suspected cases. Telephone numbers of designated health authorities were also provided on the checklists for contact and reporting of suspected cases.

Data collection. Data were collected with the aid of a structured pre-tested questionnaire and a practice observation checklist. The suitability of the tools was assessed in a pre-test with $5 \%$ of the total sample size in drug shops located in another community close to the study area (Mbaitoli community). Data were collected twice: first at baseline (April 2020) before the intervention in May 2020, and then 3 months after intervention (August 2020). The data collection was done by four trained research assistants who were grouped in twos. One group administered the questionnaire while the other observed care practices in the drug shop and recorded their observations using the pre-tested observation checklist. Data collection lasted an average of 20 to 23 minutes at each site. The research assistants were not involved in administering the intervention.

Data analysis. Exploratory data analysis was performed initially, and the summary mean scores were computed for continuously recorded variables, whereas frequency distribution was formulated for distributional data. The summary of frequencies of the respective pre- and post-intervention responses for the knowledge and attitude domains as well as the recorded observations for the practices domain were used to assign scores ranging from 1 to 20, with 20 being the highest score. The mean of the respective pre- and post- 
intervention scores were calculated. The mean gain score was then determined as the difference between the postintervention mean score and the pre-intervention mean score. A mean gain score of 1 represents $5 \%$ improvement in KAP. The effect of the intervention was established using a paired $t$-test at a $5 \%$ level. Statistical analysis was performed using Stata v. 14.1. (StataCorp, College Station, TX).

Ethical approval. Ethical approval for this study was sought and obtained from the ethical committee of the School of Health Technology, Federal University of Technology, Owerri, Nigeria, and the Imo State Ministry of Health, Owerri, Nigeria. Permission was also obtained from the Imo State chapter of the National Association of Patent Medicine Vendors. Informed written consent was obtained from all participating PMVs.

\section{RESULTS}

Characteristics of the study participants. A total of 97 drug shops with the respective PMVs were involved in this study. The characteristics of the study participants are depicted in Table 1. About $54.6 \%$ were men and $45.4 \%$ were women, $54.6 \%$ were educated at the secondary school level, and $57.7 \%$ had more than 10 years' experience in the business.

Pre- and post-intervention introductory knowledge about COVID-19. The study participants had good knowledge of the existence of, and pathological information relating to, COVID-19 Supplemental Table 1). All study participants had heard of COVID-19 prior to the intervention, with the majority (87.6\%) knowing it resulted in a pandemic. Preintervention, only $61.9 \%$ were able to identify the pathogen responsible for COVID-19 as a virus. This, however, improved to $91.8 \%$ post-intervention. Knowledge about the lack of a definite cure for COVID-19 also improved from $41.2 \%$ (pre-intervention) to $77.3 \%$ (post-intervention).

Pre- and post-intervention knowledge about symptoms, risk, and detection of COVID-19. Supplemental Table 2 shows the pre- and post-intervention knowledge of studied PMVs about symptoms, risk, and detection of COVID-19. Pre-intervention, only $23.7 \%$ were able to identify more than $70 \%$ of the symptoms of COVID-19 whereas $43.3 \%$ were able to do so post-intervention. Knowing that everyone is at greater risk of COVID-19 also improved significantly post-intervention (94.8\%) versus compared with preintervention (78.4\%), as did knowledge about the standard test for confirming the disease $(68 \%$ post-intervention versus $12.4 \%$ pre-intervention).

TABLE 1

Characteristics of the study participants $(N=97)$

\begin{tabular}{lcc}
\hline Characteristic & Frequency & Percent (\%) \\
\hline Gender & & \\
$\quad$ Male & 53 & 54.6 \\
$\quad$ Female & 44 & 45.4 \\
Education Level & 4 & 4.1 \\
$\quad$ Primary & 53 & 54.6 \\
Secondary & 36 & 37.1 \\
Tertiary & 4 & 4.1 \\
Postgraduate & 0 & 0 \\
Informal & & \\
Years of experience & 4 & 4.1 \\
$<5$ & 37 & 38.1 \\
$5-10$ & 56 & 57.7 \\
$>10$ & & \\
\hline
\end{tabular}

Pre- and post-intervention knowledge of spread and transmissibility of COVID-19. Pre- and post-intervention knowledge of the spread and transmissibility of COVID-19 among studied PMVs is shown in Supplemental Table 3. The percentage of PMVs who knew that COVID-19 is transmissible from person-to-person improved from 81.4\% (pre-intervention) to $95.9 \%$ (post-intervention). The knowledge that it spreads via respiratory droplets improved from $70.1 \%$ (preintervention) to $91.8 \%$ (post-intervention). All respondents affirmed fomite transmission of COVID-19 post-intervention (i.e., when one touches a contaminated surface and then touches the eyes, nose, and mouth without handwashing)a shift from $91.8 \%$ pre-intervention.

Pre- and post-intervention knowledge of COVID-19 preventive measures. A majority of the respondents showed reasonable knowledge about COVID-19 preventive measures, especially post-intervention (Supplemental Table 4). Pre- and post-intervention knowledge about COVID-19 preventive measures included the practice of social distancing (66.0\% pre-intervention versus $93.8 \%$ post-intervention), frequent handwashing with soap and water (91.8\% preintervention versus $95.9 \%$ post-intervention), and wearing of face masks and gloves (91.8\% pre-intervention versus 95.9 post-intervention). Respondents also knew the required physical distance in the drug shop (37.1 pre-intervention versus 79.4 post-intervention), and that isolation and prompt treatment of infected persons are effective ways of limiting the spread of COVID-19 (79.4\% pre-intervention versus 100\% post-intervention).

Pre- and post-intervention classification of COVID-19 knowledge among PMVs. Strong knowledge about COVID-19 spread and transmissibility as well as preventive practices improved to $100 \%$ post-intervention from $78.4 \%$ and $67 \%$, respectively, pre-intervention (Table 2). Pre-intervention-to-post-intervention improvements were also recorded in the following knowledge domains: introductory knowledge of the disease (52.6-91.8\%), and symptoms, risk, and detection (62.9-71.1\%).

Pre- and post-intervention attitude of studied PMVs toward COVID-19. Table 3 depicts improvement in positive attitude of studied PMVs toward COVID-19, where $72.3 \%$ pre-intervention and $95.0 \%$ post-intervention agreed that COVID-19 exists in Nigeria. About $83.5 \%$ of PMVs preintervention and $95.9 \%$ of PMVs post-intervention agreed that COVID-19-infected persons should not go to drug shops to purchase drugs for self-medication. Furthermore, 95.9\% preintervention versus $100 \%$ post-intervention agreed that they should educate their customers about COVID-19.

Pre- and post-intervention COVID-19 control-related practices among studied PMVs. Significant improvements in COVID-19-related good practices were observed, as depicted in Supplemental Table 4.The proportion of drug shops that provided running water using a suspended bucket with tap and soap for handwashing increased from $24.7 \%$ pre-intervention to $73.5 \%$ post-intervention. The percentage of PMVs who did not check their customers' temperature using any type of thermometer reduced from $71.1 \%$ pre-intervention to $33 \%$ post-intervention. PMVs who were observed to enforce physical distancing among their customers increased from $53.6 \%$ pre-intervention to $91.8 \%$ post-intervention. The percentage of studied PMVs who used the NCDC checklist to score and counsel customers 
TABLE 2

Pre- and post-intervention coronavirus disease 2019 knowledge classification $(N=97)$

\begin{tabular}{|c|c|c|c|c|c|c|c|c|}
\hline \multirow[b]{2}{*}{ Knowledge } & \multicolumn{3}{|c|}{ Pre-intervention } & \multicolumn{3}{|c|}{ Post-intervention } & \multirow[b]{2}{*}{$P$ value } & \multirow[b]{2}{*}{$t$ Value } \\
\hline & Strong, $n(\%)$ & Fair, $n(\%)$ & Poor, $n(\%)$ & Strong, $n(\%)$ & Fair, $n(\%)$ & Poor, $n(\%)$ & & \\
\hline Introductory knowledge & $51(52.6)$ & $35(36.1)$ & $11(11.3)$ & $89(91.8)$ & $8(8.2)$ & $0(0.0)$ & & \\
\hline Symptoms, risk, and detection knowledge & $61(62.9)$ & $22(22.7)$ & $14(14.4)$ & $69(71.1)$ & $17(17.5)$ & $11(11.3)$ & & \\
\hline Knowledge on spread and transmissibility & 76 (78.4) & $21(21.6)$ & $0(0.0)$ & $97(100.0)$ & $0(0.0)$ & $0(0.0)$ & & \\
\hline Preventive knowledge & $65(67.0)$ & $24(24.7)$ & $8(8.2)$ & 97 (100.0) & $0(0.0)$ & $0(0.0)$ & & \\
\hline Overall knowledge & $63(64.9)$ & $26(26.8)$ & $8(8.2)$ & $82(84.5)$ & $12(12.4)$ & $3(3.1)$ & & \\
\hline \multicolumn{9}{|l|}{ Summary: Overall Good Knowledge } \\
\hline \multicolumn{9}{|l|}{ Pre-intervention (mean \pm SD, $14.00 \pm 4.55)$} \\
\hline \multicolumn{9}{|l|}{ Post-intervention (mean $\pm \mathrm{SD}, 18.00 \pm 2.84$ ) } \\
\hline Gained score (mean $\pm S D, 4.00 \pm 3.02)$ & & & & & & & 0.001 & 5.939 \\
\hline
\end{tabular}
to 20 . Scores of 15 and greater were considered strong knowledge, scores of 10 to 14 were taken as fair knowledge, and scores less than 10 were considered poor knowledge.

also increased, from $28.9 \%$ pre-intervention to $91.8 \%$ postintervention. More drug shop operators provided COVID-19related information to their customers post-intervention (100\%) versus pre-intervention (70.1\%), and more PMVs (86.6\%) post-intervention became willing to report suspected cases to the designated response team, compared with $24.5 \%$ pre-intervention.

\section{DISCUSSION}

In most parts of Nigeria, drug shops are often the first points of care for persons with mild and moderate illnesses with symptoms similar to those of COVID-19, and generally play a significant role in the Nigerian health-care cascade. A failure to integrate drug shops into COVID-19-related strategic response plans may create significant bottlenecks in efforts to control the disease, particularly at the community and household levels. Training and sensitizing PMVs on recent developments in health, especially during epidemics/ pandemics such as that caused by COVID-19, might prove key in breaking the chain of infection in various rural and semi-urban settings. Because of the novelty of SARS-CoV2 , there has been no defined cure or vaccine for COVID-19 until recently. This emphasizes the need to maximize the use of every available resource in efforts to control the disease. PMVs hold certain key elements in unlocking the minds of community members to adhering to guidelines, rules, and regulations that have been set by the government and

TABLE 3

Pre- and post-intervention attitude of studied patent medicine vendors toward coronavirus disease $2019(N=97)$

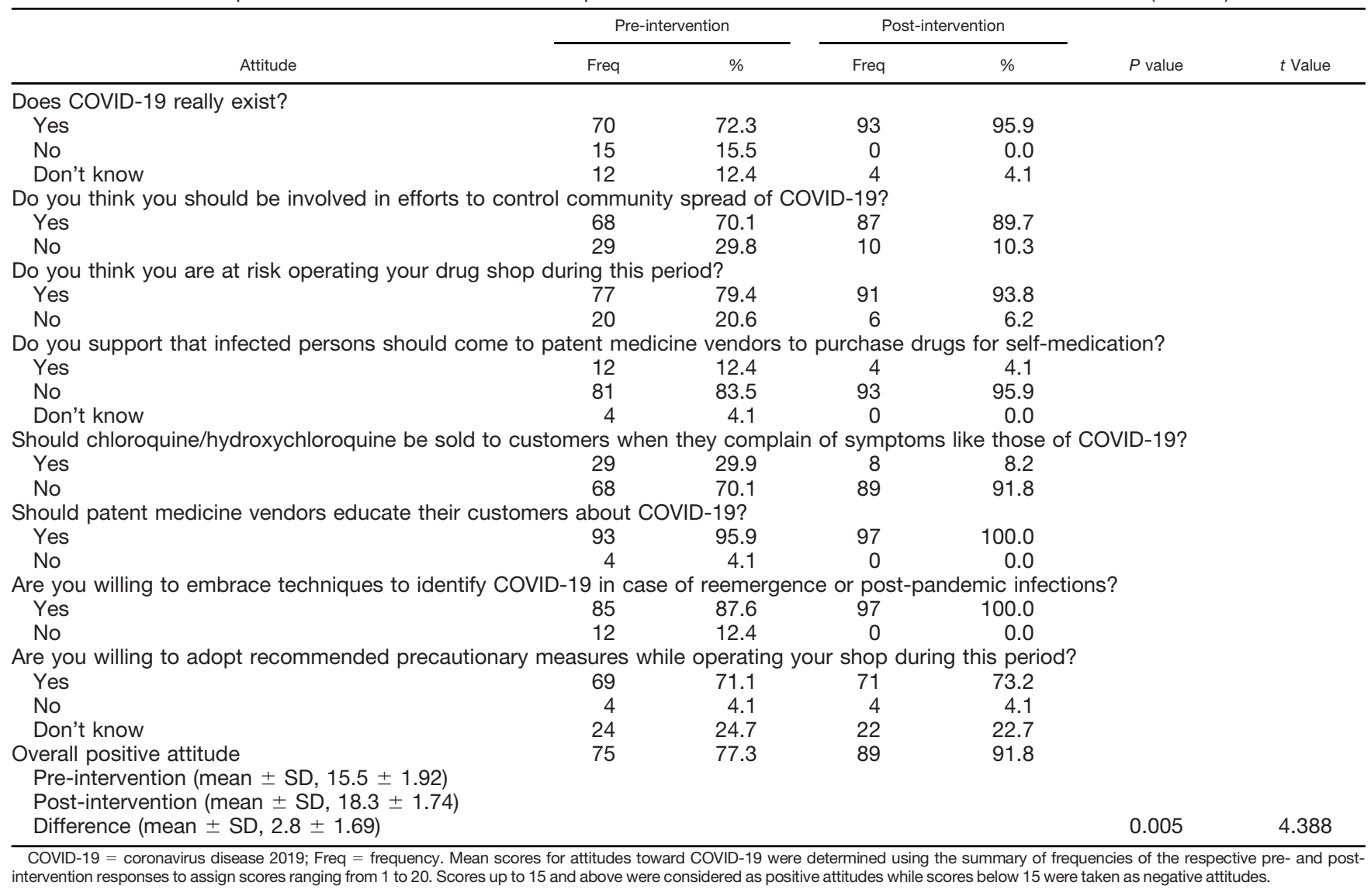


TABLE 4

Pre- and post-intervention coronavirus disease 2019 control-related practices among studied patent medicine vendors $(N=97)$

\begin{tabular}{|c|c|c|c|c|c|c|}
\hline \multirow[b]{2}{*}{ Practice } & \multicolumn{2}{|c|}{ Pre-intervention } & \multicolumn{2}{|c|}{ Post-intervention } & \multirow[b]{2}{*}{$P$ value } & \multirow[b]{2}{*}{$t$ Value } \\
\hline & Freq & $\%$ & Freq & $\%$ & & \\
\hline \multicolumn{7}{|l|}{ Handwashing facilities provided in the drug shops } \\
\hline Running tap water with soap & 12 & 12.4 & 12 & 12.4 & & \\
\hline Running bucket water with soap & 24 & 24.7 & 81 & 73.5 & & \\
\hline Basin stagnant water with soap & 0 & 0.0 & 0 & 0.0 & & \\
\hline Hand sanitizers only & 21 & 21.6 & 8 & 8.2 & & \\
\hline None & 28 & 28.9 & 0 & 0.0 & & \\
\hline \multicolumn{7}{|c|}{ Thermometer used to read body temperature of customers at the drug shop } \\
\hline Infrared thermometer & 20 & 20.6 & 57 & 58.8 & & \\
\hline Ordinary clinical thermometer & 8 & 8.2 & 8 & 8.2 & & \\
\hline None & 69 & 71.1 & 32 & 33.0 & & \\
\hline Other & 0 & 0.0 & 0 & 0.0 & & \\
\hline \multicolumn{7}{|c|}{ Strict enforcement of physical distancing among customers in the drug shop } \\
\hline Yes & 52 & 53.6 & 89 & 91.8 & & \\
\hline No & 45 & 46.4 & 8 & 8.2 & & \\
\hline \multicolumn{7}{|c|}{ Prohibition of customers from touching surfaces or objects in the drug shop } \\
\hline Yes & 56 & 57.7 & 89 & 91.8 & & \\
\hline No & 41 & 42.3 & 8 & 8.2 & & \\
\hline \multicolumn{7}{|c|}{ Keeping at least $2 \mathrm{~m}$ of physical distancing when attending to customers } \\
\hline Yes & 60 & 61.9 & 89 & 91.8 & & \\
\hline No & 37 & 38.1 & 8 & 8.2 & & \\
\hline \multicolumn{7}{|l|}{ Method of exchanging pleasantries with customers } \\
\hline Oral greeting/waving hands & 64 & 66.0 & 85 & 87.6 & & \\
\hline Handshakes & 21 & 21.6 & 4 & 4.1 & & \\
\hline Touching of arms or elbows & 12 & 12.3 & 8 & 8.2 & & \\
\hline Bowing & 4 & 4.1 & 0 & 0.0 & & \\
\hline Other & 0 & 0.0 & 0 & 0.0 & & \\
\hline \multicolumn{7}{|c|}{ Frequent wiping of surfaces and high-contact areas with alcohol-based sanitizers } \\
\hline Yes & 89 & 91.8 & 97 & 100.0 & & \\
\hline No & 8 & 8.2 & 0 & 0.0 & & \\
\hline \multicolumn{7}{|l|}{ Practice of good personal hygiene in the shop } \\
\hline Yes & 97 & 100.0 & 97 & 100.0 & & \\
\hline No & 0 & 0.0 & 0 & 0.0 & & \\
\hline Wearing of gloves while administering first aid to $\mathrm{cu}$ & & & & & & \\
\hline Yes & 85 & 87.6 & 93 & 95.9 & & \\
\hline No & 12 & 12.3 & 4 & 4.1 & & \\
\hline Practices when customers present with symptoms & ble sy & is of $\mathrm{CC}$ & 9 (feve & gh, diffic & reathing) & \\
\hline Administer normal drugs & 49 & 50.5 & 0 & 0.0 & & \\
\hline Send away & 12 & 12.4 & 4 & 4.1 & & \\
\hline Use the NCDC self-checklist for case detection & 28 & 28.9 & 93 & 95.9 & & \\
\hline Other & 4 & 4.1 & 0 & 0.0 & & \\
\hline Action when a customer scores between 12 and 28 & CDC & & & & & \\
\hline Panic and send away & 4 & 4.1 & 4 & 4.1 & & \\
\hline Counsel and call appropriate health authorities & 28 & 28.9 & 89 & 91.8 & & \\
\hline Refer to hospital & 8 & 8.2 & 4 & 4.1 & & \\
\hline Refer to herbalist & 45 & 46.4 & 0 & 0.0 & & \\
\hline Counsel and advise to contact health authorities & 8 & 8.2 & 0 & 0.0 & & \\
\hline Other (administer some drugs and send away) & 8 & 8.2 & 0 & 0.0 & & \\
\hline Provision of COVID-19-related information to custor & & & & & & \\
\hline Yes & 68 & 70.1 & 97 & 100.0 & & \\
\hline No & 29 & 29.9 & 0 & 0.0 & & \\
\hline Willingness to report suspected cases to the design & prities & & & & & \\
\hline Yes & 24 & 24.7 & 84 & 86.6 & & \\
\hline No & 69 & 71.1 & 13 & 13.4 & & \\
\hline Don't know & 4 & 4.1 & 0 & 0.0 & & \\
\hline Provision of isolation point around the shop where a & d cas & be ke & desig & authoriti & & \\
\hline Yes & 0 & 0.0 & 4 & 4.1 & & \\
\hline No & 97 & 100.0 & 93 & 95.9 & & \\
\hline Sell of COVID-19-related personal protective equipn & as $\mathrm{m}$ & ves, ha & itizers & bthers to & omers & \\
\hline Yes & 77 & 79.4 & 81 & 83.5 & & \\
\hline No & 20 & 20.6 & 16 & 16.5 & & \\
\hline Overall practice (good practice) & 58 & 59.8 & 87 & 89.7 & & \\
\hline Pre-intervention (mean $\pm \mathrm{SD}, 12.06 \pm 5.59)$ & & & & & & \\
\hline Post-intervention (mean $\pm \mathrm{SD}, 18.04 \pm 1.91$ ) & & & & & & \\
\hline Gained score (mean \pm SD, $5.98 \pm 4.70)$ & & & & & 0.007 & 4.059 \\
\hline
\end{tabular}

COVID-19 = coronavirus disease 2019; Freq = frequency; NCDC = Nigerian Center for Disease Control. Multiple responses considered. Mean scores for COVID-19-related practices were determined using the summary of frequencies of the respective pre- and post-intervention recorded observations to assign scores ranging from 1 to 20 . Scores of 15 and greater were considered good practice, whereas scores less than 15 were taken as poor practice. 
appropriate authorities to aid in the fight against COVID-19. Some of the key elements are that PMVs understand the communities in which they operate, command respect, influence the people, and are familiar with the leaders of their communities. These factors make it easy for them to convey, potentially, vital information concerning COVID-19 to community members and remind them of their responsibilities. This is because it is only when people accept and regard a source of information as trustworthy, can they begin to abide by the information.

Our study shows the PMVs were relatively knowledgeable about COVID-19 both pre- and post-intervention. Studies on COVID-19 KAP in parts of north-central Nigeria, ${ }^{14}$ and among health-care workers ${ }^{15}$ and senior pharmacy students ${ }^{16}$ all reported that respondents had good general knowledge about the disease. Our drug shop intervention, however, improved this general knowledge significantly among PMVs, particularly on specific COVID-19 knowledge domains, including knowledge about symptoms, risky behaviors, detection and diagnosis, spread and transmissibility, as well as knowledge about preventive measures. Improvements in the domains of symptom recognition, identification of risky behaviors, detection, and diagnostic procedures as well as the transmissibility of COVID19 were quite remarkable. These changes may have been triggered by the level of consciousness created by the disease, which made the intervention appealing and acceptable to the participants; hence, they were enthusiastic to learn more. The knowledge level among participants was not a surprise given that lots of COVID-19-related information was circulating the Internet and social media, although some of it may not be reliable resulting from a lack of control. Other sources of information such as radio and television could have also played a part in this. Nevertheless, the participants' perception that the disease has a definite cure poses a major concern because it can easily be a reflection of the general public's perception, such as unconfirmed information that hydroxychloroquine was a definite and recommended cure for COVID-19.

There was a significant improvement in positive attitude regarding COVID-19 post-intervention, implying the potential sustainability of the intervention. A positive attitude is important and paramount to ensuring that interventions work, and that people accept, trust, and live based on the information they receive from authorities. ${ }^{17}$ Interestingly, a reasonable number of the studied PMVs believed that COVID-19 exists in Nigeria, despite the misleading news at the time that COVID-19 was not in Nigeria and that the government was taking advantage of the global menace to embezzle money. Perhaps this is attributable to the fact that the PMVs have a slight edge over the lay public on how they perceive healthrelated challenges, given their line of business. Because these PMVs are often in steady contact with the public, they can help correct prevailing misconceptions and misinformation, especially if validated and encouraged to do so. Regrettably, only a few of them expressed satisfaction with measures put in place so far to contain the virus even after our intervention. This corroborates the report of another Nigerian study in which most of the respondents expressed dissatisfaction with the measures set by the government and appropriate authorities to control COVID-19. ${ }^{14}$ Our study participants, however, expressed their willingness to take measures against the spread of COVID-19 regardless of what the government had put in place. This suggests there could be a disconnect with the authorities that may need to be addressed properly so that everyone is onboard with ensuring that COVID-19 is controlled effectively in Nigeria. Significant improvement in terms of good practices was recorded with the intervention, as more PMVs postintervention were inclined to use face masks and gloves, and encouraged their customers to practice physical distancing, hand washing, and good personal hygiene. This improvement was also evident in the number of drug shops post-intervention with improvised running water using a suspended bucket with a tap and bowl beneath to collect the runoff water. Other practices observed to have improved in the drug shops post-intervention were enforcement of physical distancing, discouragement of customers from touching high-contact surfaces, sanitization of surfaces, and non-contact greetings. These are some of the highly recommended measures to limit the spread of COVID-19. ${ }^{18}$ Although the effective use of face masks and gloves is key to mitigating the spread of COVID-19 in the drug shops, attention needs to be paid to their quality to ensure their durability and effectiveness. For instance, some of the face masks worn by some of the respondents appeared overused, dirty, and may have been contaminated, and some PMVs were not quite sure of the alcohol content in the hand sanitizers they used. In China, the Quality Control Center once reported that many health-care workers at Hubei Province were infected with COVID-19 because of the improper use of personal protective equipment, including face masks and gloves. ${ }^{19}$ Likewise, another study in southwest and northwest Nigeria reported that only $25.7 \%$ of the study group had adequate knowledge about personal protective equipment.

Along with improvement in the rate of customer sensitization, our intervention also contributed to an increase in the rate of the use of the NCDC COVID-19 recommended checklist for case detection at the drug shops studied. Although no COVID-19 cases were reportedly confirmed from any of the shops during the study period, this is a critical aspect of the intervention that needs to be sustained because the PMVs' ability to counter further spread of COVID-19 in the community hinges on their capacity to identify and report suspected cases promptly. On the other hand, there was no significant change in the provision of a temporary isolation point at the drug shops where suspected cases may remain until the designated authorities arrive. This could have been a result of the lack of space rather than willingness to make such an area possible. The majority of the structures housing these businesses are small buildings situated along local roads. This poses a great concern, especially as response from the designated authorities may not be as prompt as it should be. Strengthening the capacity for case-finding, case detection, isolation, and prompt response is key to reducing the spread of COVID-19. ${ }^{20}$

The post-intervention behaviors recorded in our study can be sustained by adopting and integrating the intervention as part of the national COVID-19 control activities in which compliance with the recommended practices can be enforced by regulatory agencies. Text messaging could also be used to remind PMVs of these practices and sustain positive behavior. Furthermore, visual aids, such as posters displayed at strategic points in the drug shops, could serve as constant reminders for PMVs to adhere to the recommended, appropriate COVID-19-related care practices. 
Limitations. A limitation of this study included our inability to assess the extent to which drug shop operators were able to influence their customers and or community members positively to adopt and maintain good practices that disrupt the spread of infection. In addition, because of the relatively small population size and the intent to engage as many drug shops as possible, we could not introduce a control group; hence, a single-arm intervention design was adopted. While the intervention was being carried out, general public education on COVID-19 was in place, which may have contributed to the changes recorded post-intervention. However, an intervention such as this is important in delivering targeted and relevant information to ensure adequate awareness and appropriate practices among relevant groups such as the PMVs.

\section{CONCLUSION}

The level of health knowledge along with other significant factors play a major role in determining health behavior and how interventions are accepted and used. With novel infections such as COVID-19, communicating relevant, correct information to the public may help facilitate control and mitigation efforts. The findings of our study affirm that massive enlightenment as well as a positive attitude and good practices toward COVID-19 can be achieved through the introduction of interventions that strengthen community sensitization by including private-sector health-care providers in the fight against the disease. Organizing training for drug shop operators and similar players in the health-care system of Nigeria should always be considered. This is because it may help create a more universal approach to responding to emergencies caused by contagious diseases and may even improve the quality of services provided at the drug shops. This measure is evidently needed in Nigeria and other developing nations, where most health services are provided primarily outside government-owned facilities and most are financed through out-of-pocket spending. Furthermore, the engagement and integration of these critical community health stakeholders are of additional value during post-pandemic surveillance to ensure that residual cases are detected and handled promptly and adequately. Drug shop operators could also play important roles in the enlightenment of community members regarding COVID-19 issues, including sensitization and mobilization for vaccinations. Failure to engage and involve critical stakeholders in community health-care delivery, such as PMVs, may foster community transmission of COVID19 and exacerbate the pressure on the already weak health infrastructure to meet the health demands of the people.

This study has demonstrated the drug shop intervention to be effective in enhancing the KAP of PMVs in engaging them in efforts to contain COVID-19. It has the potential for sustainability and scalability because of its acceptance, cost-effectiveness, simplicity, and ease of implementation. It is, however, necessary to carry out large-scale studies to explore its real impact in combating the pandemic, particularly in sub-Saharan Africa and other low-resource countries.

Received December 6, 2020. Accepted for publication April 26, 2021.

Published online June 15, 2021.

Note: Supplemental tables appear at www.ajtmh.org.

Acknowledgments: We acknowledge the support of the Ministry of Health, Imo State, the National Association of Patent Medicine
Vendors, Imo State Chapter, and the National Association of Seadogs-especially Okechukwu Madukwe, Chijioke Obi, Obinna Igbokwe, Udochukwu Onuegbu, Ikenna Opara, and others-for their support of this work. We also thank the individual PMVs who participated in this study as well as all the research assistants involved. The American Society of Tropical Medicine and Hygiene has waived the Open Access fee for this article due to the ongoing COVID-19 pandemic and has assisted with publication expenses.

Authors' addresses: Uchechukwu Madukaku Chukwuocha, Gregory Ndubeze Iwuoha, Onyeka Francis Ashinze, Princewill Ugochukwu Njoku, Chidera Chisom Obasi, Evelyn Ifezue Adey, and Ikechukwu Nosike Simplicius Dozie, Department of Public Health, Federal University of Technology, Owerri, Imo State, Nigeria, E-mails: uchukwuocha@ gmail.com, gregiwuoha@gmail.com, onyekashinze18@gmail.com, njoku174@gmail.com, deraobasi@gmail.com, ifezuefivecrew@gmail. com, and dozieins@yahoo.com.

This is an open-access article distributed under the terms of the Creative Commons Attribution (CC-BY) License, which permits unrestricted use, distribution, and reproduction in any medium, provided the original author and source are credited.

\section{REFERENCES}

1. Gorbalenya AE et al., 2020. The species severe acute respiratory syndrome-related coronavirus: classifying 2019-nCoV and naming it SARS-CoV-2. Nat Microbiol 5: 536-544.

2. CDC, 2020. How COVID-19 Spreads. Available at: www.cdc. gov/coronavirus. Accessed August 15, 2020.

3. Mueller AL, McNamara MS, Sinclair DA, 2020. Why does COVID19 disproportionately affect older people? Aging (Albany NY) 12: 9959-9981.

4. Haybar H, Kazemnia K, Rahim F, 2020. Underlying chronic disease and COVID-19 infection: a state-of-the-art review. Jundishapur J Chronic Dis Care 9: e103452.

5. WHO, 2020. Coronavirus disease (COVID-19) Situation Report82. Available at: https://www.who.int/emergencies/diseases/ novel-coronavirus-2019. Accessed April 26, 2020.

6. World Bank, 2018. Poverty and Shared Prosperity: Piecing Together the Poverty Puzzle. Available at: https://www. worldbank.org/en/publication/poverty-and-shared-prosperity2018. Accessed April 12, 2020.

7. Nigeria Center for Disease Control, 2020. State of the Nation: COVID-19 Situation Report 39. Available at: https://ncdc.gov. $\mathrm{ng} /$ themes/common/files/sitreps/3c6296efefa303dd06bdd1a2a 7f30ea4.pdf. Accessed April 16, 2020.

8. The World Bank, 2020. Operational Planning Guidelines to Support Country Preparedness and Response. Available at: https://www.worldbank.org/en/publication/poverty-and-sharedprosperity-2018. Accessed May 5, 2021.

9. British Broadcasting Center, 2020. Coronavirus: Why Some Nigerians Are Gloating about COVID-19. Available at: https://www. bbc.com/news/world-africa-52372737. Accessed May17, 2020.

10. Beyeler N, Liu J, Sieverding M, 2015. A systematic review of the role of proprietary and patent medicine vendors in healthcare provision in Nigeria. PLoS One 10: e0117165.

11. Mayora $\mathrm{C}$ et al., 2020. Private retail drug shops: what they are, how they operate, and implications for health care delivery in rural Uganda. BMC Health Serv Res 18: 532.

12. Okeke TA, Uzochukwu BS, 2009. Improving childhood malaria treatment and referral practices by training patent medicine vendors in rural south-east Nigeria. Malar J 8: 260.

13. Onwujiariri CM, Nwachi CC, Nkwocha EE, 2017. Rural healthcare service provision and implication in rural development of Imo State, Nigeria. Int J Lat Eng Res App 2: 13-22.

14. Reuben RC, Danladi MMA, Saleh DA, Ejembi PE, 2020. Knowledge, attitudes and practices towards COVID-19: an epidemiological survey in north-central Nigeria. J Community Health 7: 1-14.

15. Ogolodom MP, Mbaba AN, Alazigha N, Erondu OF, Egbe NO, Golden I, Ugwuanyi DC, Achi Gl, Eke CM, 2020. Knowledge, attitudes and fears of healthcare workers towards the corona virus disease (COVID-19) pandemic in south-south, Nigeria. Health Sci J 1: 002. 
16. Hamza MS, Badary OA, Elmazar MM, 2020. Cross-sectional study on awareness and knowledge of COVID-19 among senior pharmacy students. $J$ Commun Health 15: 1-8.

17. Okoro $\mathrm{J}$ et al., 2020. Attitude and preventive practices toward COVID-19 disease and the impact of awareness training on knowledge of the disease among correctional officers. Emerald Open Res 2: 51.

18. Sohrabi C, Alsafi Z, O'Neill N, Khan M, Kerwan A, Al-Jabir A, Losifidis C, Agha R, 2020. World Health Organization declares global emergency: a review of the 2019 novel coronavirus (COVID-19). Int J Surg 76: 71-76.

19. Wang J, Zhou M, Liu F, 2020. Reasons for healthcare workers becoming infected with novel coronavirus disease 2019 (COVID-19) in China. J Hosp Infect 105: 100-101.

20. WHO, 2020. Coronavirus Disease 2019 (COVID-19) Situation Report-72. Available at: https://www.who.int/docs/default-source/ coronaviruse/situation-reports/20200401-sitrep-72-covid-19.pdf. Accessed October 4, 2020. 